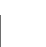

Rev. Latinoam. Psicopat. Fund., São Paulo, v. 11, n. 3, p. 470-474, setembro 2008

\title{
Mortalidade por transtornos mentais e comportamentais e a reforma psiquiátrica no Brasil contemporâneo - II. Elementos para um debate
}

Fernando Portela Câmara

O aumento da mortalidade na categoria dos transtornos mentais e comportamentais - face à redução progressiva das internações hospitalares promovida pela reforma psiquiátrica em curso - tem aquecido o debate entre os proponentes da reforma e parte da comunidade psiquiátrica brasileira. Neste artigo, analisa-se os argumentos dos reformistas.

Palavras-chave: Mortalidade por transtornos mentais e comportamentais, reforma psiquiátrica, política de saúde mental brasileira 
Assistimos hoje no Brasil a uma luta entre os que supostamente propõem acabar com o modelo médico-psiquiátrico e os que o defendem. Câmara (2007a, 2007b) mostrou como a psiquiatria se definiu como especialidade médica ao adotar o método clínico, proposto inicialmente por Khalbaum e Hecker, e assentado em bases científicas por Kraepelin (Câmara, 2007b). Este modelo evoluiu até os dias atuais para o diagnóstico, sua epidemiologia, o aperfeiçoamento da classificação psiquiátrica e o tratamento medicamentoso, impulsionando notável desenvolvimento científico da farmacologia, e a hospitalização dos doentes (incluindo aqui os dependentes químicos) para sua recuperação e retorno à sociedade.

Contra este modelo insurgiu-se um movimento, em parte ideológico, cujo modelo está atualmente em implantação no país. Trata-se, basicamente, da negação da doença mental e sua óbvia atribuição a um estigma social forjado pelas "elites" (tendo a "corporação" médica como artífice) contra pessoas menos capazes de conviver numa dinâmica social competitiva. O movimento culpa a "corporação" médica pela invenção da doença mental e ataca a posição contrária de muitos psiquiatras à "reforma psiquiátrica" ora em curso no país, denunciando-a como fruto de um corporativismo em que os psiquiatras não engajados querem "retomar o velho espaço de poder no campo da saúde, como no projeto do Ato Médico" (Machado, 2008, p. 17).

A reportagem publicada pelo jornal $O$ Globo (2007), e que denuncia o aumento de mortes de doentes mentais e comportamentais nos últimos cinco anos - coincidente com a queda progressiva das internações hospitalares - foi criticada pelo atual coordenador de Saúde Mental do Ministério da Saúde com base em fatos que, ao serem citados, não são esclarecidos. Senão vejamos:

Em entrevista a uma revista (Machado, 2008), o coordenador contesta dizendo que a reportagem não levou em consideração "o aprimoramento do Sistema de Informações sobre Mortalidade (SIM) na captação de dados" (p. 16), mas não dá nenhuma explicação sobre o que seja isso. Ora, os dados em questão são definitivos e aceitáveis, e a única base para análises usada pelo próprio Ministério da Saúde. Câmara (2008) mostrou que a análise usada era insuficiente, porque não foi considerado o aumento da população residente no país. Uma vez feita esta correção, revelou-se um progresso real na redução de mortalidade no SUS para certas categorias de doenças, porém a mortalidade na categoria de transtornos mentais e comportamentais (CID-10) permaneceu ainda muito elevada, e não há como negar isso a partir dos dados disponibilizados.

$\mathrm{O}$ entrevistado prossegue dizendo que o que ocorreu foi "um aumento da mortalidade, no mesmo período, em quase todas as categorias diagnósticas, segundo estudo preliminar da Secretaria de Vigilância em Saúde do Ministério da 
Saúde” (p. 16). E continua: “... por exemplo, ‘doenças do aparelho geniturinário’ e 'doenças neurológicas' tiveram incremento semelhante ao do grupo 'transtornos mentais e do comportamento', e não houve redução de leitos ou mudança de modelo de atenção" (p. 16). Ora, essas categorias podem superpor-se numa só, sendo necessário eliminar essa possibilidade para afirmar o fato aludido. É sabido o alto grau de superposição entre síndromes psiquiátricas e neurológicas, bastando citar o exemplo das demências, do retardo mental e das epilepsias. Por outro lado, o doente mental raramente procura o serviço médico para se tratar de doenças somáticas, salvo casos evidentes, especialmente na área geniturinária. Essas observações da clínica cotidiana invalidam o argumento exposto na entrevista, requerendo uma explicação detalhada.

Em uma revisão sobre mortalidade em pacientes psiquiátricos, Sampaio e Caetano (2006) encontraram suficiente evidência que mostram que o doente mental tem uma expectativa de vida significativamente menor que a da população geral, e que internados em um hospital são protegidos e melhor assistidos, reduzindose a mortalidade a níveis comparáveis à população geral. Os autores, em face dos dados, revelaram preocupação com o projeto brasileiro de desospitalização e sugerem o desenvolvimento de estratégias e programas preventivos. No mesmo trabalho, os autores mostram a significativa incidência de co-morbidades por doenças naturais em doentes psiquiátricos (câncer, pneumonias, cardiopatias, hipertensão etc.) e mortalidade por tais causas, que nas estatísticas médicas são computadas nas respectivas categorias, obscurecendo a condição primária de paciente psiquiátrico.

Na continuação, lemos a seguinte afirmação: “... não há aumento real da mortalidade (...) mas melhoria na captação de dados" (p. 16). Ora, se houve melhoria na captação de dados, então o aumento da mortalidade ficou estabelecido definitivamente, o que já sabemos; portanto, a afirmação da proposição contradiz a anterior. Também a afirmação de que "não é possível fazer uma relação direta (...) do aumento de morte por transtornos mentais e diminuição de leitos psiquiátricos" (ibid.), e, mais adiante, a conclusão de que: "apesar disso (...) acredita que são necessários novos estudos, inclusive qualitativos, para melhor apropriação de todos os dados disponíveis" (ibid.), são argumentos contraditórios.

Mais adiante, ainda na mesma entrevista, lemos o argumento central de toda essa questão, a defesa do projeto da "reforma psiquiátrica", que é a abolição do modelo hospitalar em todo país: "Entre 2002 e 2006 forma reduzidos 11.826 leitos em hospitais psiquiátricos convencionais (...). Ao mesmo tempo, as residências terapêuticas passaram de 85 para 475 (...) e os Centros de Atenção Psicossocial (Caps) de 424 para 1.011..." (ibid.). Fica patente que não está em jogo a questão da mortalidade, mas a implantação e implementação de um projeto que, dentre outras coisas, resultou num aumento considerável nos postos de 
trabalho para a saúde mental. Andreoli et al. (2007) avaliam que a cobertura do projeto de implantação do modelo Caps ainda é precária e a reforma da assistência psiquiátrica não foi acompanhada pelo aumento em investimento público em saúde mental. Isto sugere o efeito colateral de uma desassistência que pode culminar em um aumento de mortalidade? Também sugere que o modelo em questão talvez seja bem mais caro que o hospitalar ou não esteja recebendo os recursos necessários.

De qualquer forma, qualquer crítica referente à associação entre redução de leitos e aumento de mortalidade (suficientemente regular para garantir uma conclusão estatisticamente fundamentada, com erro tipo I mínimo, ver Câmara, 2008), não se sustenta ante a evidência dos fatos referentes às estatísticas de redução de leitos e de mortalidade na categoria de transtornos mentais e do comportamento. É hora de se deixar as ideologias de lado e todos sentarem-se à mesa para encontrar o modelo mais viável e mais seguro para assistir esta população desprotegida e vulnerável que é a dos pacientes psiquiátricos, e seus familiares que tanto sofrem.

Financiamento deste trabalho: nenhum

Conflito de interesses neste trabalho: nenhum

\section{Referências}

Aggege, S. O governo não quer saber de quem ouve vozes. $O$ Globo, Rio de Janeiro, 9 dez. 2007, O País, p. 15.

Andreoli, S.B.; Almeida-Filho, N.; Martin, D.; Mateus, M.D.M.L.; Mari, J.J. Is psychiatric reform a strategy for reducing the mental health budget? The case of Brazil. Revista Brasileira de Psiquiatria, São Paulo, v. 29, n. 1, p. 43-46, 2007.

CÂmara, F.P. A catástrofe de Kraepelin. Revista Latinoamericana de Psicopatologia Fundamental, São Paulo, v. 10, n. 2, p. 307-318, jun.2007a.

. A construção do diagnóstico psiquiátrico. Revista Latinoamericana de Psicopatologia Fundamental, São Paulo, v. 10, n. 4, p. 677-684, dez.2007b.

. Mortalidade por transtornos mentais e comportamentais e a reforma psiquiátrica no Brasil contemporâneo. Revista Latinoamericana de Psicopatologia Fundamental, São Paulo, v. 11, n. 2, p. 278-285, jun.2008.

Machado, K. Ataque à Reforma Psiquiátrica Brasileira. Radis, Rio de Janeiro, n. 67, p. 16-17, mar.2008.

SAmpaio, A.L.P.; CAEtano, D. Mortalidade em pacientes psiquiátricos: revisão bibliográfica. Jornal Brasileiro de Psiquiatria, Rio de Janeiro, v. 55, n. 3, p. 226-231, 2006. 


\section{Resumos}

(Mortalidad por trastornos mentales y de comportamiento y la reforma psiquiátrica en el Brasil contemporáneo - II. Elementos para un debate)

El incremento de la mortalidad en la categoría desordenes mentales y del comportamiento - concerniente a la reducción progresiva de camas psiquiátricas tiene acalorado la discusión entre los que proponen la reforma y parte de la comunidad psiquiátrica brasileña. En este artículo se analizan los argumentos de los reformistas. Palabras claves: Mortalidad por disturbios mentales y de comportamiento, reforma psiquiátrica, política de la salud mental brasileña

(Mortalité par désordres mentaux et comportementaux et la réforme psychiatrique au Brésil contemporain - II. Eléments pour un débat)

L'augmentation de la mortalité dans la catégorie des désordres mentaux et comportementaux - face à la réduction progressive des lits psychiatriques préconisée par la réforme psychiatrique en cours - a attisé le débat entre les réformistes et une partie de la communauté psychiatrique brésilienne. Cet article analyse les arguments des réformistes.

Mots clés: Mortalité par désordres mentaux et comportementaux, réforme psychiatrique, politique de la santé mentale brésilienne

(Death from mental and behavioral disturbances and psychiatric reform in contemporary Brazil II. - Elements for a debate)

The rising death rate in the category of mental and behavioral disorders - related to the progressive reduction in the number of psychiatric beds - is bringing new elements to the discussion between reformists and some sectors of the Brazilian psychiatric community. In this paper, the arguments of the reformists are analyzed.

Key words: Mental and behavioral disturbances, mortality, psychiatric reform, Brazilian mental health policies

Versão inicial recebida em julho de 2008

Versão aprovada para publicação em julho de 2008

\section{Fernando Portela Câmara}

MD; PhD; Professor associado, SEDI-IMPPG-UFRJ - Setor de Epidemiologia de Doenças Infecciosas do Instituto de Microbiologia Professor Paulo de Góes, da Universidade Federal do Rio de Janeiro (Rio de Janeiro, RJ, Brasil).

Rua Pinheiro Machado, 25/405

22231-090 Rio de Janeiro, RJ, Brasil

Fone: (21) 9618-8603

e-mail: fp3camara@yahoo.com.br 